\title{
Lysosomal iron in pulmonary alveolar proteinosis: a case report
}

\author{
H.L. Persson*,\# and L.K. Vainikka\#,
}

ABSTRACT: Pulmonary alveolar proteinosis is characterised by accumulation of surfactant-like material in the distal air spaces. Since lysosomes play a crucial role for degradation of large biomolecules taken up from the cell's environment, it was hypothesised that oxidant-induced lysosomal disruption and ensuing cell death might play a role in disease development.

In the present study, alveolar macrophages, harvested by whole-lung lavage from a patient diagnosed with pulmonary alveolar proteinosis, are shown to contain large amounts of undigested material within lysosomes, and the same organelle exhibits increased amounts of haemosiderin-bound iron. Compared with murine macrophage-like J774 cells (iron exposed or not), the status of human macrophages was pro-oxidative, i.e. macrophages exhibited a low level of the antioxidant glutathione and large amounts of iron available for Fenton-type chemistry. As a consequence, macrophageal lysosomes were particularly fragile when exposed to physiological concentrations of hydrogen peroxide (generated by glucose oxidase in culture medium). Such lysosomal disruption resulted in extensive cell death by both necrosis and apoptosis independent of caspase-3 activation.

Considering the potential role of iron-catalysed oxidant-induced lysosomal rupture and ensuing cell killing for pulmonary alveolar proteinosis pathology and disease progression, whole-lung lavage might be considered early in those cases in which cytochemical staining reveals great numbers of haemosiderin-laden alveolar macrophages.

\section{KEYWORDS: Alveolar macrophages, ferritin, lung lavage, lysosomes, oxidative stress}

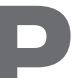
ulmonary alveolar proteinosis (PAP) is a rare lung disorder [1]. PAP is characterised by a dense accumulation of surfactant-like material composed of phospholipids and proteins, typically deposited in alveoli and bronchioles $[2,3]$. The primary form of PAP is most common [2,3]. Reduced macrophageal clearance of surfactant is caused by decreased activity of the granulocyte-macrophage colonystimulating factor (GM-CSF), due to the presence of neutralising antibodies against GM-CSF $[2,3]$. Other forms, secondary to haematological malignancies or exposure to inorganic dust (e.g. silica and aluminium), results in surfactant accumulation by a numerical deficiency of alveolar macrophages (AMs) and/or functional impairment of these cells to degrade surfactant $[2,3]$.

Lysosomes play a crucial role for the cell's iron metabolism by continuously degrading cytosolic iron-containing elements (e.g. "worn-out" mitochondria and ferritin) and large biomolecules taken up from the environment [4-6]. Degradation products (i.e. metals, amino acids, monosaccharides, etc.) are delivered to the cytosol for re-use [4-6]. Due to a highly reductive intra-lysosomal milieu, liberated iron largely exists in a redox-active status inside lysosomes [7-9]. In the presence of hydrogen peroxide $\left(\mathrm{H}_{2} \mathrm{O}_{2}\right), \mathrm{Fe}^{2+}$ catalyses Fentontype chemistry, by which hydroxyl radicals damage lysosomal membranes [10, 11]. Massive lysosomal disruption results in necrosis, while apoptosis follows more moderate lysosomal leakage [10, 11].

Oxidant-induced macrophageal cell death is a proposed mechanism in lung inflammation and fibrosis development [10, 12]. Transmission electron microscopy (TEM) studies of PAP-AMs demonstrate an abundance of lysosomes filled with material in the process of degradation [3]. Indeed, PAP-AMs are thought to die overfed by excessive amounts of surfactant [13]. Considering the pivotal role of macrophageal lysosomes for PAP pathology, the present authors hypothesised that an oxidant-induced lysosomal pathway of cell death might be of some importance.

\section{AFFILIATIONS}

Divisions of *Pulmonary Medicine

"Experimental Pathology, and

"Otorhinolaryngology, Faculty of

Health Sciences, University of

Linköping, Linköping, Sweden.

CORRESPONDENCE

H.L. Persson

Dept of Pulmonary Medicine

University Hospital

SE-581 85 Linköping

Sweden

Fax: 4613221529

E-mail: Lennart.Persson@lio.se

Received:

March 212008

Accepted after revision:

August 192008

\section{SUPPORT STATEMENT}

The present study was financially supported by the LiÖ Research Funds (Östergötland, Sweden), the Medical Research Council of Southeast Sweden and local fundings from the Dept of Pulmonary Medicine and the Centre of Surgery and Oncology (University Hospital, Linköping, Sweden; grants to H.L. Persson).

STATEMENT OF INTEREST None declared. 


\begin{tabular}{lc}
$\begin{array}{l}\text { TABLE } 1 \\
\text { Pulmonary function test }\end{array}$ & \\
\hline VC & Volume L (\% pred) \\
\hline FEV 1 & $6.4(113)$ \\
TLC & $5.2(112)$ \\
RV & $7.6(100)$ \\
DL,CO & $1.3(74)$ \\
\hline
\end{tabular}

VC: vital capacity; FEV1: forced expiratory volume in one second; TLC: total lung capacity; RV: residual volume; $\mathrm{LL}, \mathrm{CO}$ : diffusing capacity of the lung for carbon monoxide.

\section{PATIENT PRESENTATION}

A nonsmoking male (aged $22 \mathrm{yrs}$ ) was referred to the Department of Pulmonary Medicine (University Hospital, Linköping, Sweden) because of a routinely performed chest radiograph revealing discrete bilateral infiltrates (but was otherwise normal). On high-resolution computed tomography $(\mathrm{HRCT})$, these infiltrates had a ground glass appearance. The patient was asymptomatic and had no previous history of exposure, medication or diseases. Apart from slightly elevated lactate dehydrogenase (LDH), complete blood count and chemistry profile were normal. Pulmonary function tests were normal (table 1).

The patient performed $160 \%$ of predicted $(350 \mathrm{~W})$, but the alveolar-arterial oxygen tension difference $\left(P A--a, \mathrm{O}_{2}\right)$ difference was elevated at maximal work rate (fig. 1). Differential cell counts in bronchoalveolar lavage (BAL) fluid was normal, cultures (including Mycobacteria) were negative, CD4/CD8 ratio was slightly low and cytological examination was without signs of inflammation or neoplasia. Transbronchial biopsy specimens were not diagnostic, while open lung biopsy specimens, obtained by video-assisted thoracoscopy, were

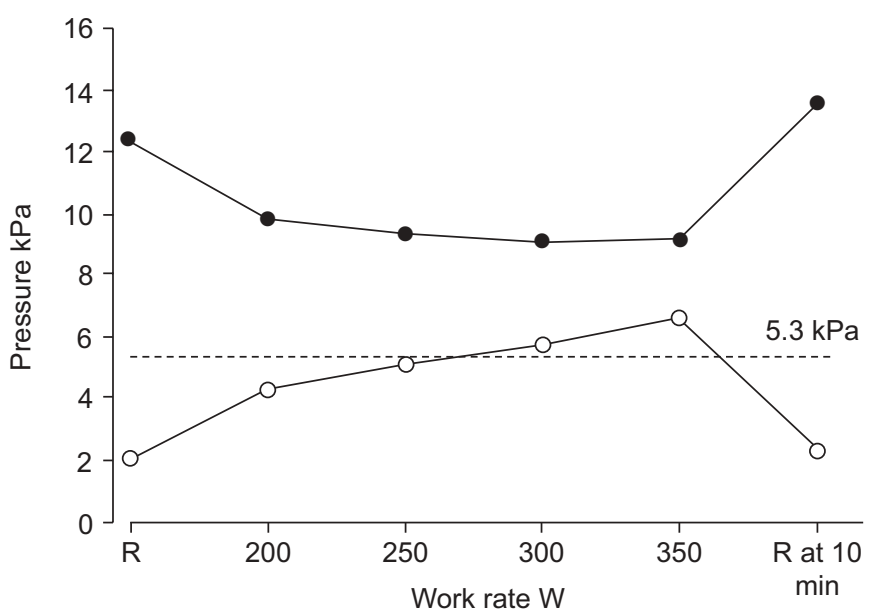

FIGURE 1. Response of arterial oxygen tension $\left(\mathrm{Pa}_{2} \mathrm{O}_{2} ; \bullet\right)$ and alveolar-arterial oxygen tension difference $\left(\mathrm{PA}_{\mathrm{A}-\mathrm{a}, \mathrm{O}_{2} ; O} \mathrm{O}\right)$ to exercise before whole-lung lavage. Compared with values at rest $(\mathrm{R})$, significant changes of $\mathrm{Pa}_{\mathrm{a}, \mathrm{O}_{2}}$ and $\mathrm{PA}-\mathrm{-a}, \mathrm{O}_{2}$ became evident during excercise. $\mathrm{PA}-\mathrm{a}, \mathrm{O}_{2}>5.3 \mathrm{kPa}$ is a criterion for when to proceed to whole-lung lavage [3].
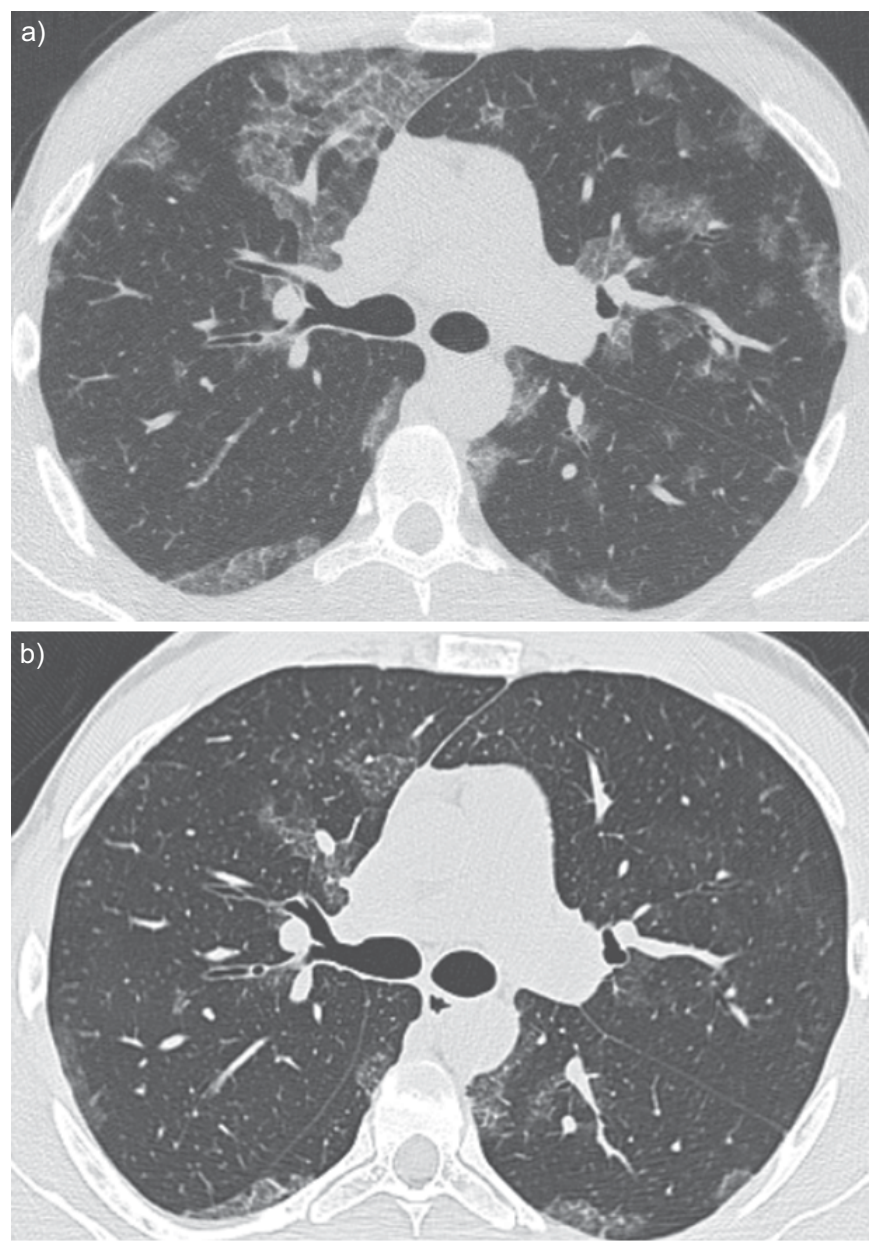

FIGURE 2. Chest high-resolution computed tomography (HRCT) performed a) before and b) after whole-lung lavage (WLL). a) Pre-WLL HRCT shows patchy geographic ground-glass attenuation with superimposed intra- and interlobular septal thickening. The polygonal appearance, representing secondary lobules, is referred to as "crazy-paving". b) Note the significant improvement following WLL of both lungs

characteristic for PAP. In time, the patient experienced some shortness of breath with exercise but was otherwise asymptomatic, lung function and performance during exercise were preserved but a second HRCT (performed 13 months after the first one) demonstrated progression of infiltrates (fig. 2a). Whole-lung lavage (WLL) was therefore performed as previously described [3]. Under general anaesthesia and independent lung ventilation, the right lung was infused with normal saline (NS) at $37^{\circ} \mathrm{C}$. Tidal washing volume was $1,000 \mathrm{~mL}$ for each cycle. $23 \mathrm{~L}$ of NS were infused during chest percussion until clearing of the lavage effluent. Cultures were negative. The left lung was lavaged with $26 \mathrm{~L}$ of NS 4 weeks later. HRCT, performed 1 month after the second WLL, revealed a significant improvement (fig. $2 b$ ).

\section{MATERIALS AND METHODS}

\section{Ethical considerations}

The study protocol was approved by the local ethical committee (Linköping, Sweden) according to the guidelines of the Helsinki declaration. Fully informed consent was obtained before WLL 
and written consent was obtained for publication of medical history, radiological images and study results.

\section{Cell cultures and treatments}

Due to initial methodological problems, the data presented derives from the second WLL only. AMs, harvested from the recovery of the first cycle of lavage (performed without chest percussion), were filtered through a nylon filter (pore diameter $100 \mu \mathrm{m}$; Syntab Product AB, Malmö, Sweden), centrifuged $\left(400 \times g, 10 \mathrm{~min}, 4^{\circ} \mathrm{C}\right)$ and rinsed in PBS $\left(4^{\circ} \mathrm{C}\right)$. Murine macrophage-like histiocytic lymphoma (J774) cells were used as a reference. Cells were cultured in Dulbecco's Modified Eagle's Medium (DMEM; GIBCO, Paisley, UK) supplemented with $10 \%$ fetal bovine serum (FBS), $100 \mathrm{IU} \cdot \mathrm{mL}^{-1}$ penicillin and $100 \mu \mathrm{g} \cdot \mathrm{mL}^{-1}$ streptomycin at standard culture conditions $\left(37^{\circ} \mathrm{C}\right.$ and humidified air with $5 \% \mathrm{CO}_{2}$ ).

Cells were seeded in $35 \mathrm{~mm}$ Petri dishes, rinsed in PBS and attached cells $\left(0.4 \times 10^{6}\right.$ cells $\cdot$ dish $\left.^{-1}\right)$ were returned to standard culture conditions for $36 \mathrm{~h}$. J774 cells were exposed (or not) to a stock solution of $\mathrm{FeCl}_{3}$ added directly to the medium $\sim 8 \mathrm{~h}$ before oxidant challenge. In the medium, $\mathrm{FeCl}_{3}$ forms a hydrated Fe-phosphate complex, which is phagocytosed by the cells and ends up in the lysosomes.

Cells were oxidatively stressed for $60 \mathrm{~min}$ at standard culture conditions by adding a stock solution of glucose oxidase (GO; Sigma-Aldrich Inc., St. Louis, MO, USA) directly to the culture medium. The concentration used generates a stable concentration of $\mathrm{H}_{2} \mathrm{O}_{2}(\sim 40-60 \mu \mathrm{M})$, thus mimicking the conditions in vivo.

\section{Prussian blue staining technique and the sulphide silver method}

The Prussian blue staining procedure was used to assess haemosiderin-bound nonreactive $\mathrm{Fe}\left(\mathrm{Fe}^{3+}\right)$ in PAP-AMs and J774 cells (the latter exposed to $0-100 \mu \mathrm{M} \mathrm{FeCl}_{3}$ ) [14].

Cells were ranked for haemosiderin content using the following scale. 0 : no colour; 1: faint blue in a part or the whole cytoplasm with or without single deep granules; 2: medium colour intensity throughout the cytoplasm with or without dark blue granules in minor $(<50 \%)$ portions of the cytoplasm; 3: deep blue granules in major $(>50 \%)$ portions of the cytoplasm; or 4 : deep blue granules throughout the cell [15]. A haemosiderin score (HS) was calculated per 100 cells. A score of 0-20 was regarded as low, 21-100 as intermediate and $>100$ as high [15].

In control experiments, Prussian blue stained J774 cells (Feexposed or not) were compared with J774 cells stained for lysosomal ferrous $\mathrm{Fe}\left(\mathrm{Fe}^{2+}\right)$ using the sulphide silver method (SSM) $[9,16]$. A typical lysosome-sized silver precipitation pattern corresponds to Fe-deposits within lysosomes, as shown by TEM $[16,17]$.

\section{Analysis of reduced glutathione and total cellular iron}

Samples for reduced glutathione (GSH) analysis were prepared by collecting the cells in $0.5 \mathrm{M} \mathrm{HClO}_{4}$ supplemented with $1 \mathrm{mM}$ EDTA. Following centrifugation $(300 \times g$, $10 \mathrm{~min}$, $4{ }^{\circ} \mathrm{C}$ ), supernatants were used for assessment of intracellular GSH using high-performance liquid chromatography (HPLC) [18]. Fe was measured in cell lysates using a Z-8270 Polarised Zeeman atomic absorption spectrophotometer (Hitachi, Kyoto, Japan) equipped with an Fe lamp (243.3 nm). GSH and Fe concentrations were calculated from standard curves and normalised by the protein concentration of each sample (protein was determined by the bicinchoninic acid method, using egg albumin as a standard).

\section{Lysosomal membrane integrity assay}

Acridine orange (AO; Gurr, Poole, Dorset, UK) is a metachromatic fluorophore and a lysosomotropic base $(\mathrm{pKa}=10.3)$. It is retained in its charged form $\left(\mathrm{AOH}^{+}\right)$by proton trapping inside the acidic vacuolar compartment, preferentially in secondary lysosomes ( $\mathrm{pH} 4-5)$. When highly concentrated within intact lysosomes, $\mathrm{AO}$ exhibits red fluorescence. Lysosomal membrane damage was therefore monitored cytofluorometrically as a decrease in $\mathrm{AO}$ red fluorescence $[5,7]$.

\section{Determination of caspase-3 activation}

The fluorescence of AMC (7-amino-4-methyl-coumarin), liberated from Ac-DEVD-AMC (Becton Dickinson, Mountain View, CA, USA) by active caspase-3-like caspases, was analysed at an excitation wavelength of $380 \mathrm{~nm}$ and emission wavelength of $435 \mathrm{~nm}$ in a Shimadzu RF-1501 spectrofluorophotometer (Shimadzu, Kyoto, Japan).

\section{Evaluation of apoptotic DNA and cell morphology}

The fraction of fragmented apoptotic DNA was determined cytofluorometrically using propidium iodide (PI; Sigma Chemical Co., St. Louis, MO, USA) [19]. The same method was applied to assess the amount of low-fluorescent PI-stained material (silica particles and large biological particles such as surfactant) liberated from the cells' interior/lysosomal vacuome following cell lysis.

The frequency of cells with apoptotic or necrotic morphology (i.e. cytoplasmic budding and pycnotic or fragmented nuclei and membranous rupture or cellular/nuclear swelling, respectively) was also estimated.

\section{Statistical analysis}

Results are given as mean \pm SD. Statistical comparisons were made using ANOVA.

\section{RESULTS}

\section{Haemosiderin-bound ferric Fe is located mainly within the} Iysosomes

AMs stained robustly for haemosiderin-bound $\mathrm{Fe}^{3+}$ (fig. 3a). Indeed, all cells scored 3 or more, giving a haemosiderin score (HS) per 100 cells $>300$. Simultaneously stained J774 control cells (i.e. negative control) exhibited only small amounts of haemosiderin ( $\mathrm{HS}<3$ ). J774 cells exposed to increasing concentrations of $\mathrm{Fe}$ (positive controls) displayed haemosiderin-bound $\mathrm{Fe}^{3+}$ in a dose-dependent manner. Only J774 cells exposed to $100 \mu \mathrm{M} \mathrm{FeCl}{ }_{3}$ demonstrated $\mathrm{HS}$ in the same range as cultures of AMs.

Next, the staining pattern of Prussian blue was compared with silver precipitation using SSM. Following phagocytosis, $\mathrm{FeCl}_{3}$ was administered to lysosomes, therefore preferentially increasing $\mathrm{Fe}$ deposits within this organelle. Both Prussian blue granularity and silver precipitation were distributed within J774 cells in a way typical for lysosomes (fig. 3b shows results using SSM) and increased dose-dependently following lysosomal Fe loading with $\mathrm{FeCl}_{3}$. 

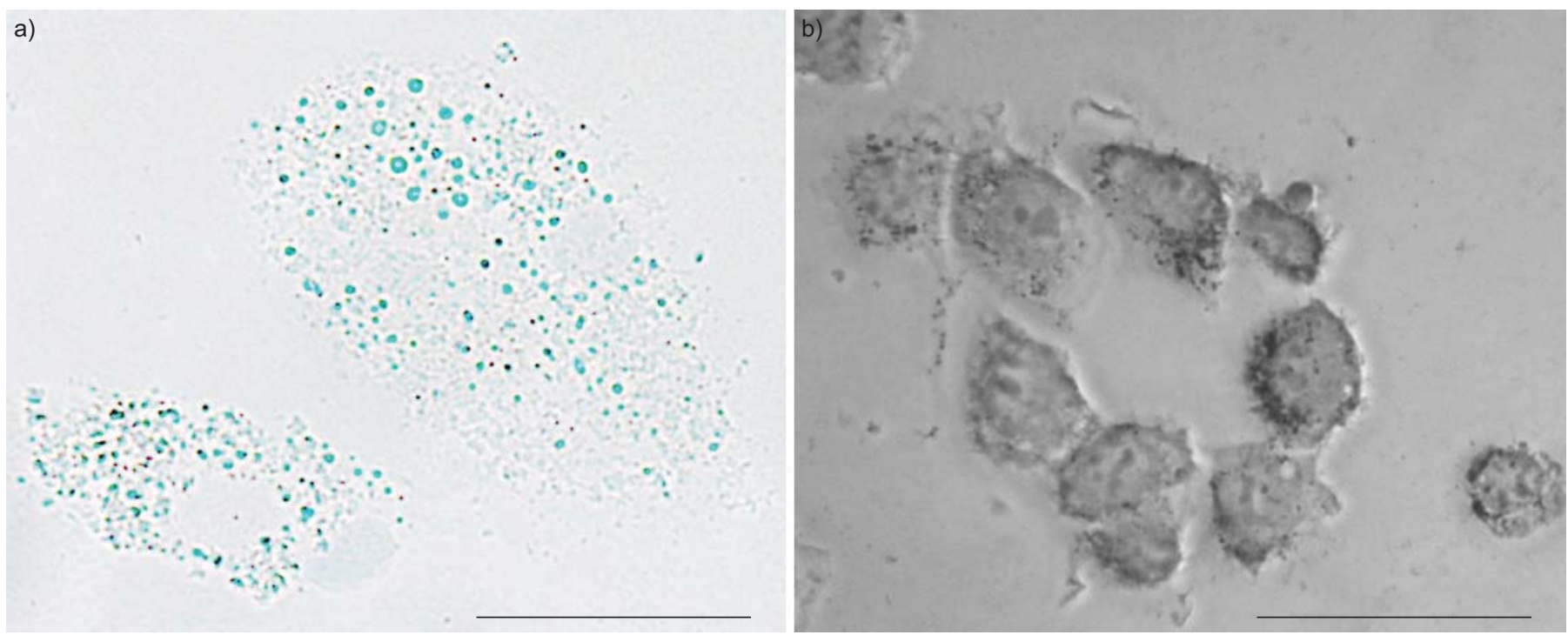

FIGURE 3. Cytochemical demonstration of a) ferric Fe in pulmonary alveolar proteinosis alveolar macrophages using the Prussian blue technique, and b) ferrous Fe in iron-exposed $\mathrm{J} 774$ cells by the sulphide silver method. a) Prussian blue granularity in a perinuclear distribution corresponding to lysosomes (typically for pulmonary alveolar proteinosis, alveolar macrophages are very large). b) Silver precipitation in $\mathrm{J774}$ cells following $\mathrm{FeCl}_{3}$-exposure (100 $\mu \mathrm{M}$ ) colocalise to lysosomes (cells developed 20 min) No counterstaining used. Scale bars $=50 \mu \mathrm{m}$.

\section{Lysosomes of AMs contain large amounts of undegraded material}

From TEM studies of PAP-AMs [13] and silica-exposed AMs [20-22], it is known that lysosomal degradation of surfactantlike material in time becomes impaired. The lysosomal vacuome becomes expanded by accumulating amounts of undigested material [3]. This scenario is, in the light microscope, reflected by foamy AMs containing numerous vacuoles (fig. 4a). Upon cell lysis, such material is released in vivo into the alveolar space [13] and in vitro into the culture medium [23].

In the present experimental setting, this was evident when AMs lysed in a hypotonic PI solution were analysed cytofluorometrically. Indeed, PAP-AMs (not oxidatively stressed) exhibited a great fraction of low-fluorescent particles, which clearly were not derived from DNA (fig. 4b). In control experiments, J774 cells exposed to silica particles demonstrated a similar flow cytometrical pattern. In these experiments, cells were protected against harmful silica-induced plasma membrane damage by protein-coating the particles before use [23]. Following phagocytosis, particles remain inside lysosomes and, when cells are lysed, they are released into the PI solution (fig. 4c).

\section{The redox balance of AMs is pro-oxidative}

Supporting the Prussian blue studies, AMs contained a large amount of Fe (table 2), comparable with that of J774 cells exposed to $25-50 \mu \mathrm{M} \mathrm{FeCl}_{3}$ for $8 \mathrm{~h}$. The concentration of GSH was, on the other hand, much lower in AMs (table 2). GSH scavenges free radicals and may act as a cofactor for peroxidases in the glutathione family, through which $\mathrm{H}_{2} \mathrm{O}_{2}$ is reduced to $\mathrm{H}_{2} \mathrm{O}$. Notably, in J774 cells cellular level of GSH decreased by exposure to increasing concentrations of $\mathrm{Fe}$, indicating that $\mathrm{Fe}$, per se, has a great impact on cells' anti-oxidative status.
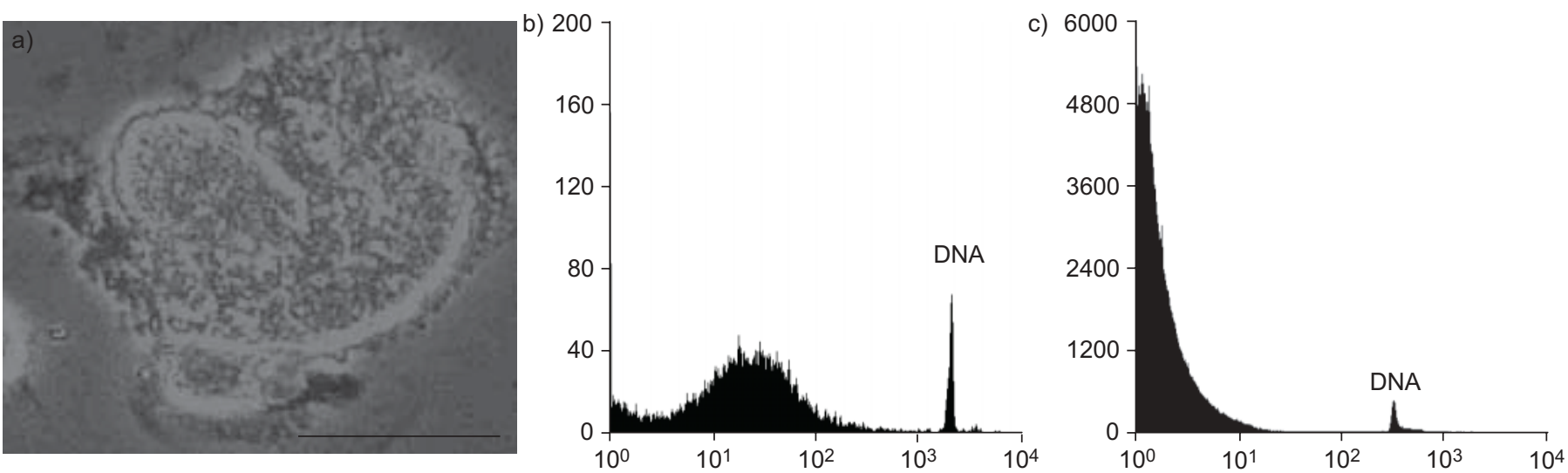

FIGURE 4. Assessment of intra-cellular material. a) Light micrograph of a foamy macrophage containing numerous vacuoles. Cytofluorometric pattern of b) pulmonary alveolar proteinosis alveolar macrophages and c) $\mathbf{J} 774$ cells (previously exposed to protein-coated silica particles) following lysis in propidium iodide solution. Opposed to propidium iodide-stained DNA (as indicated), material from ruptured lysosomes, i.e. phospholipids and silica particles, appear as a great fraction of low-fluorescent events (no gating performed). Scale bar $=50 \mu \mathrm{m}$. 
A low level of GSH and an excess of Fe is likely to set the delicate balance of cellular oxidants and antioxidants in favour of a pro-oxidative status. Given that intra-lysosomal Fentontype chemistry mainly depends on the influx of $\mathrm{H}_{2} \mathrm{O}_{2}$ (escaping degradation in the cytosol) and the amount of available lysosomal reactive $\mathrm{Fe}$ [7-11], macrophageal lysosomes are expected to be very susceptible to oxidative stress.

\section{Oxidative stress causes lysosomal damage and macrophageal cell death independent of caspase-3 activation}

By assessing emitted AO-induced red fluorescence, which is proportional to the size of the lysosomal vacuome [16], the lysosomal compartment of AMs were found to be much greater than that of J774 cells (Fe-exposed or not; fig. 5a). Upon oxidant exposure, AMs demonstrated pronounced lysosomal disruption, reflected by a decrease of $\mathrm{AO}$ red fluorescence during the first hour after completed oxidant challenge (fig. 5b). Lysosomes of J774 cells were more stable but became fragile following Fe-loading (fig. 5b). In J774 cells committed to apoptosis, a significant increase of caspase- 3 activity was noted at $5 \mathrm{~h}$ after oxidant challenge (fig. $5 \mathrm{c}$ ), thus occurring much later than lysosomal disruption. In contrast, dying AMs did not exhibit caspase-3 activity (fig. 5c), most likely because cell death mainly was due to necrosis.

For both cell types, apoptotic cells were frequent at 10-12 h after completed oxidant challenge but necrotic cells dominated in dishes containing oxidatively stressed PAP-AMs (fig. 6a). Regarding apoptosis, flow cytometric analysis of apoptotic DNA gave a similar result (fig. 6b).

Clearly, oxidant-induced cell killing (frequency and mode) occurs in proportion to the magnitude of preceding lysosomal leakage. These observations are in line with previous kinetic studies of the apoptotic cascade taking place within oxidantchallenged J774 cells. Starting with intralysosomal Fenton-type chemistry (assessed by electron paramagnetic resonance (EPR) in the absence or presence of lysosome-targeting Fe chelators), ensuing lysosomal leakage causes a loss of mitochondrial membrane potential and an activation of caspases, ultimately leading to DNA degradation and apoptotic morphology $[8,9,24]$.

\section{DISCUSSION}

A lysosomal pathway of cell killing is proposed to play a role for inflammatory lung disease $[10,12]$ but, to the present authors' knowledge, this idea has never been tested on human AMs. Here, for the first time it is shown that lysosomes of AMs, harvested from a patient suffering from PAP, are very susceptible to oxidative stress. Pronounced lysosomal disruption gave rise to extensive cell death, mainly by necrosis. In contrast, J774 cells exhibited only moderate lysosomal damage following exposure to $\mathrm{H}_{2} \mathrm{O}_{2}$ and, consequently, cell death was mainly due to apoptosis. This difference is partly explained by a very low level of GSH in PAP-AMs, thereby letting greater amounts of $\mathrm{H}_{2} \mathrm{O}_{2}$ to diffuse into lysosomes and react with Fe.

Surprisingly, however, PAP-AMs were found to contain excessive amounts of haemosiderin-bound lysosomal $\mathrm{Fe}$, further sensitising lysosomes and cells to oxidant challenge. Since all data derive from the second WLL, it might be argued that the great number of haemosiderin-laden AMs was caused by a bleeding in the alveolar space, in turn being a result of barotrauma during single-lung ventilation. In the present authors' opinion, this possibility is less likely. This patient did not exhibit any clinical or radiological signs of post-WLL haemorrhage. In the case of a subclinical lung bleeding, most, if not all, haemosiderin-laden AMs would be cleared by the lung during the time passed (4 weeks) between the two procedures [25]. Moreover, the HS of PAP-AMs was extremely high (>300), a finding not likely to be explained by a pulmonary bleeding, since only conditions presenting with acute severe alveolar haemorrhage, such as vasculitis and Goodpasture's syndrome, exhibit HS higher than 100 [15].

Previous reports describing haemosiderin-laden AMs in PAP patients are scarce. TEM studies of AMs obtained from patients suffering from lysinuric protein intolerance, an even rarer condition presenting with PAP-like pathology, reveal a marked intra-macrophageal accumulation of Fe [26]. The case records of the Massachusetts General Hospital provides interesting in vivo observations [27]. A 42-yr-old female was admitted to the intensive care unit because of severe dyspnoea. Numerous haemosiderin-laden AMs were found in BAL fluid [27]. Conditions causing alveolar bleeding were thoroughly ruled out and the PAP diagnosis was obtained by open lung biopsy [27]. Very recently, in fact while we were finalising our own work, GHIO et al. [28] reported that Fe homeostasis is severely disrupted in the lungs of patients with idiopathic PAP. A severalfold increase of $\mathrm{Fe}$, transferrin, transferrinreceptors, lactoferrin and ferritin was found in cell-free WLL fluid $(n=20)$ [28]. In line with the present results, excessive amounts of $\mathrm{Fe}$ and ferritin were found in AMs and lung tissues of PAP patients [28]. Because of depressed levels of ascorbate, urate and GSH in WLL fluid, metal-catalysed oxidative stress was suggested as a mechanism involved in PAP [28].

For some time, the present authors' group [5,9] and others [6] have argued that release of Fe from the Fe-storing protein ferritin requires lysosomal degradation of the protein shell. Partial or

TABLE 2 Total cellular Fe and reduced glutathione (GSH) in alveolar macrophages (AMs) and J774 cells

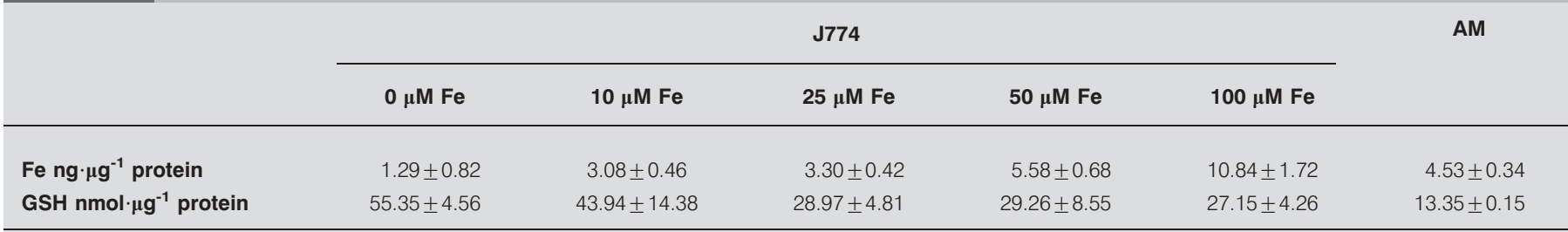

Data are presented as mean \pm SD. $J 774$ cells were exposed to increasing concentrations of $\mathrm{FeCl}_{3}$ (or not) for $8 \mathrm{~h}$ ( $\mathrm{n}=2$ ). 

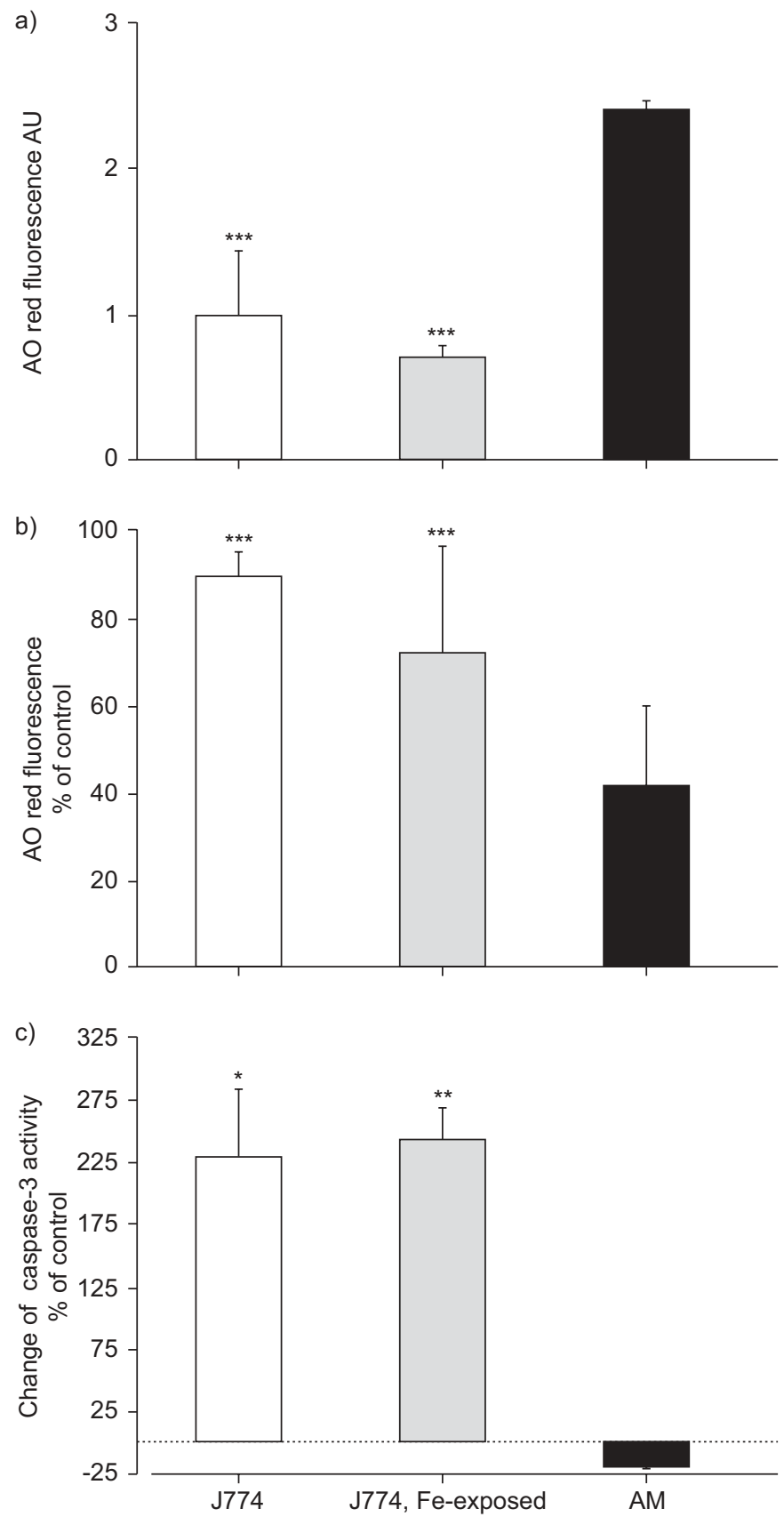

FIGURE 5. Assessment of a) lysosomal size, b) lysosomal integrity and c) caspase-3 activation. $\mathbf{J} 774$ cells, pre-exposed (or not) to $\mathrm{FeCl}_{3}$ for $8 \mathrm{~h}$, and pulmonary alveolar proteinosis alveolar macrophages (PAP-AMs) were oxidatively stressed (or not) by a stable concentration of $\mathrm{H}_{2} \mathrm{O}_{2}$, generated by adding glucose oxidase to culture medium for $1 \mathrm{~h}$, and then re-incubated at standard culture conditions until analysis. a) Lysosomal compartment size was estimated as the red fluorescence emitted from acridine orange (AO)-loaded intact lysosomes in nonoxidatively stressed cells and expressed in arbitrary units (AU). b) Oxidantinduced lysosomal membrane damage, appearing during the first $\mathrm{h}$ after ended oxidant challenge, was evaluated as the decrease of red $\mathrm{AO}$ fluorescence intensity (expressed as \% of control). c) Change of caspase-3 activity from control (\%) at $5 \mathrm{~h}$ after completed oxidative stress. Data are presented as mean $\pm S D, n \geqslant 2$. Pair-wise comparisons were made using ANOVA. *: $p<0.05$; ${ }^{* *}: p<0.01$; ${ }^{* *}: p<0.001$; all significant differences versus PAP-AMs.
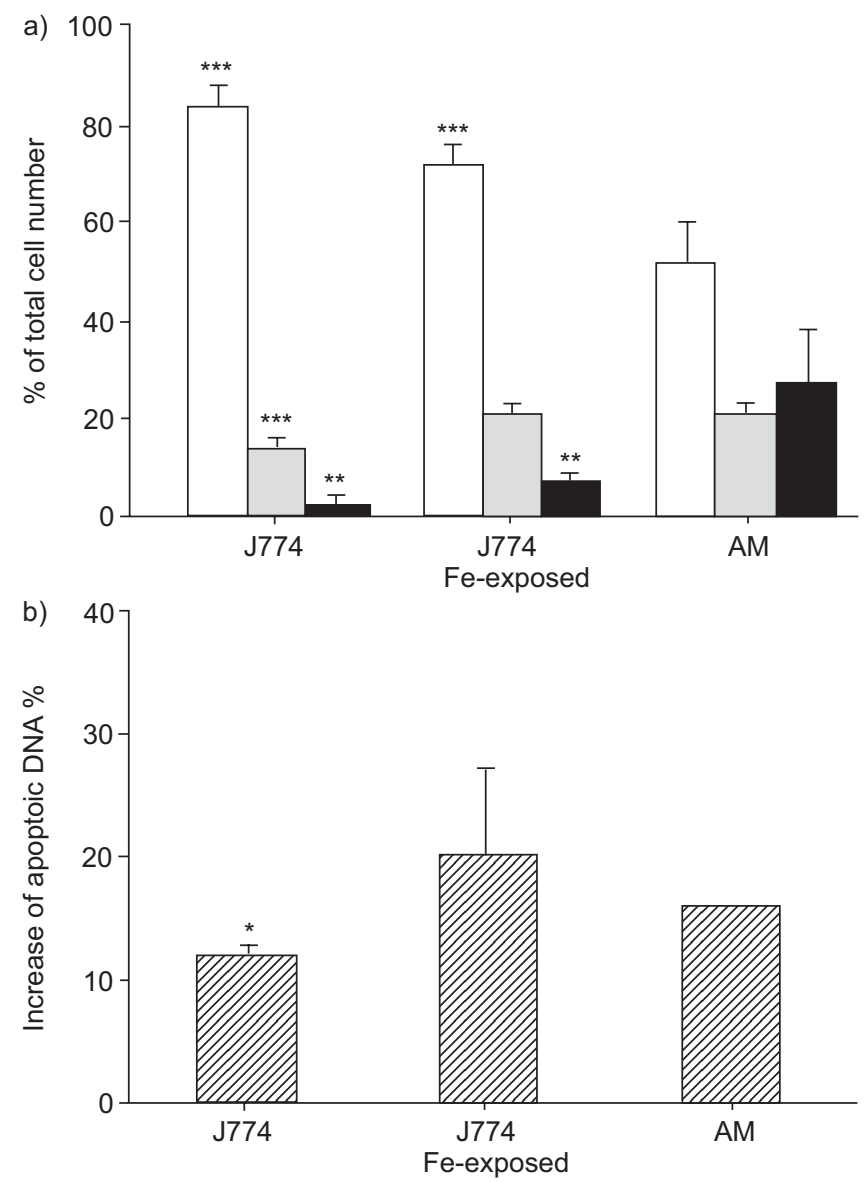

FIGURE 6. Cell death assays. a) The frequency of cells with apoptotic or necrotic morphology was estimated by light microscope 10-12 $\mathrm{h}$ after completed oxidative stress. b) Assessment of the fraction of hypodiploid DNA from apoptotic cells was performed at $10 \mathrm{~h}$ after completed oxidative stress. Data are presented as mean $\pm S D, n \geqslant 2$. Pair-wise comparisons were made using ANOVA. $\square$ : viable cells; II: apoptotic cells; $\mathbf{\square}$ : necrotic cells. *: $p<0.05$; ${ }^{* *}: p<0.01$; ${ }^{* *}: p<0.001$; all significant differences versus oxidatively stressed pulmonary alveolar proteinosis alveolar macrophages (AMs).

incomplete intra-lysosomal degradation of ferritin results in an aggregation of haemosiderin inside secondary lysosomes [29]. If normal lysosomal degradation is impaired by large amounts of intralysosomal material taken up by AMs, a logical consequence would be that the number of haemosiderin-positive AMs increases due to accumulating amounts of material within the alveolar space. Therefore, the cytology specimen of the BAL fluid was reviewed (from the initial bronchoscopy performed while disease progression still was mild) and it was found that the number of haemosiderin-laden AMs was far less in BAL fluid than in the WLL fluid. Indeed, HS of AMs in BAL was 95, thus much lower than that of AMs in WLL (HS > 300). This way of assessing disease progression may be more sensitive than traditional methods, i.e. lung function test and HRCT.

\section{Conclusions}

Very much is still not known about the nature and prognosis of pulmonary alveolar proteinosis. Although whole-lung lavage is the accepted treatment, it is still not clear when to proceed to this procedure and what the effects of this therapy are on 
prognosis. It is known, however, that some of these patients tend to deteriorate severly, eventually developing lung fibrosis. Considering the results of the present study in the light of the study by GHIO et al. [28], it seems reasonable to assume that Fe-catalysed oxidant-induced lysosomal rupture and ensuing macrophageal cell killing is involved in pulmonary alveolar proteinosis pathology. Assessment of lysosomal $\mathrm{Fe}$, in the clinical setting reflected by the number of haemosiderin-laden alveolar macrophages in bronchoalveolar lavage fluid, might serve as a marker of disease progression and prognosis. The present authors propose that alveolar macrophages are routinely stained for haemosiderin when pulmonary alveolar proteinosis is suspected and, in cases of haemosiderin-laden alveolar macrophages in bronchoalveolar lavage, consider to proceed to whole-lung lavage already in an early phase of the disease.

\section{ACKNOWLEDGEMENTS}

The present authors would like to thank U. Johansson (Division of Experimental Pathology, Faculty of Health Sciences, Linköping, Sweden) for his highly appreciated and excellent technical assistance, K. Öllinger (Division of Experimental Pathology), S. Sörenson, A.K. Munir, C. Sederholm and P. Jakobsson (Department of Pulmonary Medicine, Linköping, Sweden) for their kind help in reviewing the paper prior to submission.

\section{REFERENCES}

1 Rosen SH, Castleman B, Liebow AA. Pulmonary alveolar proteinosis. N Engl J Med 1958; 258: 1123-1142.

2 Doerschuk CM. Pulmonary alveolar proteinosis - is host defense awry? N Engl J Med 2007; 356: 547-549.

3 Shah PL, Hansell D, Lawson PR, Reid KB, Morgan C. Pulmonary alveolar proteinosis: clinical aspects and current concepts on pathogenesis. Thorax 2000; 55: 66-77.

4 De Duve C. In: F.H. Dingle JT ed. Lysosomes in Biology and Pathology (volume 1). Amsterdam, North-Holland Publishing Company, 1969; pp. 3-40.

5 Persson HL, Nilsson KJ, Brunk UT. Novel cellular defenses against iron and oxidation: ferritin and autophagocytosis preserve lysosomal stability in airway epithelium. Redox Rep 2001; 6: 57-63.

6 Kidane TZ, Sauble E, Linder MC. Release of iron from ferritin requires lysosomal activity. Am J Physiol Cell Physiol 2006; 291: C445-C455.

7 Persson HL, Svensson AI, Brunk UT. $\alpha$-Lipoic acid and $\alpha$ lipoamide prevent oxidant-induced lysosomal rupture and apoptosis. Redox Rep 2001; 6: 327-334.

8 Persson HL, Yu Z, Tirosh O, Eaton JW, Brunk UT. Prevention of oxidant-induced cell death by lysosomotropic iron chelators. Free Radic Biol Med 2003; 34: 1295-1305.

$9 \mathrm{Yu} \mathrm{Z,} \mathrm{Persson} \mathrm{HL,} \mathrm{Eaton} \mathrm{JW,} \mathrm{Brunk} \mathrm{UT.} \mathrm{Intralysosomal}$ iron: a major determinant of oxidant-induced cell death. Free Radic Biol Med 2003; 34: 1243-1252.

10 Persson HL, Richardson DR. Iron-binding drugs targeted to lysosomes: a potential strategy to treat inflammatory lung disorders. Expert Opin Investig Drugs 2005; 14: 997-1008.

11 Persson HL. Radiation-induced lysosomal iron reactivity: implications for radioprotective therapy. IUBMB Life 2006; 58: 395-401.
12 Mateos F, Brock JH, Pérez-Arellano JL. Iron metabolism in the lower respiratory tract. Thorax 1998; 53: 594-600.

13 Prakash UB, Barham SS, Carpenter HA, Dines DE, Marsh HM. Pulmonary alveolar phospholipoproteinosis: experience with 34 cases and a review. Mayo Clin Proc 1987; 62: 499-518.

14 Sundberg RD, Broman H. The application of the Prussian blue stain to previously stained films of blood and bone marrow. Blood 1955; 10: 160-166.

15 Grebski E, Hess T, Hold G, Speich R, Russi E. Diagnostic value of hemosiderin-containing macrophages in bronchoalveolar lavage. Chest 1992; 102: 1794-1799.

16 Persson HL, Kurz T, Eaton JW, Brunk UT. Radiationinduced cell death: importance of lysosomal destabilization. Biochem J 2005; 389: 877-884.

17 Zdolsek JM, Roberg K, Brunk UT. Visualization of iron in cultured macrophages: A cytochemical light and electron microscopic study using autometallography. Free Radic Biol Med 1993; 15: 1-11.

18 Honegger CG, Langemann H, Krenger W, Kempf A. Liquid chromatographic determination of common watersoluble antioxidants in biological samples. J Chromatogr 1989; 487: 463-468.

19 Nicoletti I, Migliorati G, Pagliacci MC, Grignani F, Riccardi C. A rapid and simple method for measuring thymocyte apoptosis by propidium iodide staining and flow cytometry. J Immunol Methods 1991; 139: 271-279.

20 Golde DW, Territo M, Finley TN, Cline MJ. Defective lung macrophages in pulmonary alveolar proteinosis. Ann Intern Med 1976; 85: 304-309.

21 Johansson A, Camner P. Adverse effects of metals on the alveolar part of the lung. Scan Electron Microsc 1986; 2: 631-637.

22 Lee KP, Gilles PJ. Pulmonary response and intrapulmonary lipids in rats exposed to bismuth orthovanadate dust by inhalation. Environ Res 1986; 40: 115-135.

23 Persson HL. Iron-dependent lysosomal destabilization initiates silica-induced apoptosis in murine macrophages. Toxicol Lett 2005; 159: 124-133.

$24 \mathrm{Yu}$ Z, Eaton JW, Persson HL. The radioprotective agent, amifostine, suppresses the reactivity of intralysosomal iron. Redox Rep 2003; 8: 347-355.

25 Epstein CE, Elidemir O, Colasurdo GN, Fan LL. Time course of hemosiderin production by alveolar macrophages in a murine model. Chest 2001; 120: 2013-2020.

26 Parto K, Mäki J, Pelliniemi LJ, Simell O. Abnormal pulmonary macrophages in lysinuric protein intolerance. Ultrastructural, morphometric, and x-ray microanalytic study. Arch Pathol Lab Med 1994; 118: 536-541.

27 Case records of the Massachusetts General Hospital. Weekly clinicopathological exercises. Case 2-2001. A 42year-old woman with acute worsening of chronic dyspnea and cough. New Engl J Med 2001; 344: 212-220.

28 Ghio AJ, Stonehuerner J, Richards JH, et al. Iron homeostasis and oxidative stress in idiopathic pulmonary alveolar proteinosis: a case-control study. Resp Res 2008; 9: 10 .

29 Koorts AM, Viljoen M. Ferritin and ferritin isoforms I: structure-function relationships, synthesis, degradation and secretion. Arch Physiol Biochem 2007; 113: 30-54. 